\title{
STICKY PANE MONITORING OF FROGGATT'S APPLE LEAFHOPPER AND TWO BENEFICIAL INSECTS IN THREE ORCHARD MANAGEMENT SYSTEMS
}

\author{
D.M. SUCKLING, A.R. GIBB and G.M. BURNIP \\ HortResearch, P.O. Box 51, Lincoln, Canterbury, New Zealand \\ Corresponding author: msuckling@hortresearch.co.nz
}

\begin{abstract}
A convenient monitoring system for a range of pipfruit arthropods was investigated as part of the development of Integrated Fruit Production for apples. The monitoring system, based on clear sticky panes, was used to monitor adults of Froggatt's apple leafhopper (Edwardsiana crataegi) and two beneficial insects (Sejanus albisignata and Micromus tasmaniae) in Canterbury apple orchards under three management regimes over three seasons. The results reconfirmed the presence of two generations of Froggatt's apple leafhopper and S. albisignata in Canterbury. Differences in pest and beneficial insect abundance were evident between the three orchard production systems. Numbers of S. albisignata were consistently lowest in the conventional fruit production system, but this was not the case for M. tasmaniae or E. crataegi.

Keywords: apple, phenology, apple leafhopper, Sejanus albisignata,
\end{abstract} Micromus tasmaniae.

\section{INTRODUCTION}

The recent development of Integrated Fruit Production in New Zealand pipfruit (Batchelor et al. 1997) has required an unprecedented understanding of the significance of pests and diseases by both researchers and growers. As part of this development process, the monitoring and management of pipfruit pests and beneficials was investigated over several years. The development of an entirely new pest management system involved inherent risk. New systems for monitoring a range of pipfruit arthropods were needed at a research level (Suckling et al. 1996) in order to better understand the changing levels of pests as the system evolved. Later, practical recommendations for orchardists were developed, usually with simpler approaches, such as decision support systems based on monitoring using pheromone traps (Bradley et al. 1998).

Ideally, sampling systems for pipfruit arthropods would be easy, cost-effective, without apparent bias and universal for all organisms of interest. However, the wide ranging differences in pest and beneficial biology, and especially mobility, make this objective unobtainable, except for a narrow range of species. Teulon \& Penman (1984) found that attractive yellow sticky boards, with removable plastic sheets, were an effective monitoring tool for Froggatt's apple leafhopper (FALH), Edwardsiana crataegi (Douglas) (Homoptera: Cicadellidae). However, for the study reported in this paper, an unbiased passive trap was preferred in order to sample E. crataegi and two predatory species, a mirid and a lacewing. Sejanus albisignata (Knight) (Miridae) is a generalist predatory bug attacking codling moth eggs and first instar larvae (Wearing \& Charles 1989), European red mites Panonychus ulmi Koch (Walker et al. 1989) and two spotted mites (Tetranychus urticae Koch) (Thomas \& Walker 1989), and possibly E. crataegi eggs (Charles 1989). Sejanus albisignata has also been observed feeding directly on eggs of apple leafcurling midge Dasineura mali (Kieffer) (A.R. Gibb, unpubl. data). In orchards, Micromus tasmaniae Walker (Neuroptera) larvae are most commonly associated with aphids, however, they may also be found feeding on thrips, scale insects, mites and other small insects (Collyer \& van Geldermalsen 1975). This paper reports the 
development and use of a monitoring system using clear sticky panes in three orchard management systems over three years.

\section{Orchards}

\section{MATERIALS AND METHODS}

The study was conducted in three apple blocks, cv. Fuji on MM106 rootstock, at the Horticulture Research Area at Lincoln University. All three blocks were managed with the same conventional insecticide and fungicide programme in 1994/95, prior to the introduction of the three different orchard production systems in 1995/96. The Integrated Fruit Production (IFP) and Biological Fruit Production (BFP) blocks consisted of three 0.3 ha areas of mature cv. Fuji on MM106 rootstock, $4.4 \mathrm{~m}$ in height, with row spacings of $4.5 \mathrm{~m}$ and tree spacings of $3.0 \mathrm{~m}$, and trained to a slender pyramid shape. These adjacent blocks had originally been part of the same 0.6 ha block. The Conventional Fruit Production block was similar, but larger in area (1 ha), and located $300 \mathrm{~m}$ to the north east of the other two treatments. The surrounding land use was predominantly orchard under conventional management, and pasture. There were no known infestations of blackberry in the area.

\section{Orchard management systems}

The three orchard production systems have been reported elsewhere (Suckling et al. 1999). The IFP block received applications of the selective insecticide tebufenozide against leafrollers and codling moth on three occasions during the 1995/96 season (December, January, February) and on two occasions during the 1996/97 season (December, January) and 1997/98 season (December, February). No other insecticides were applied to the block. Disease control was achieved by minimal use of conventional fungicides, and hydrated lime. The understorey was managed as a $1 \mathrm{~m}$ wide herbicide strip (glyphosate). In the BFP block, pest and disease management consisted of up to four applications of Bacillus thuringiensis (Yates Thuricide HP, $100 \mathrm{~g} / 100$ litre) per season against leafrollers, along with sulphur, copper and hydrated lime for black spot and powdery mildew control. The understorey was managed through the application of pea straw mulch. The CFP block received four applications of azinphosmethyl at approximately monthly intervals from November to February, with the December application replaced by chlorpyrifos. Conventional fungicides were applied at regular intervals from November to April in keeping with standard commercial practice in Canterbury (total of 12 applications). The understorey was managed as a herbicide strip (glyphosate) to the area under the drip line. Pre-bloom oils (DC-Tron) were applied to all three treatments at the label rate. The central alleyway was mowed in all cases.

\section{Sticky pane trap development}

Sticky pane traps (consisting of $300 \mathrm{~mm}$ x $300 \mathrm{~mm}$ sheets of clear $3 \mathrm{~mm}$ perspex) were coated with either a thin rolled film of STPTM oil treatment (STP) or grease (Mobil EPO 23), in the season before the three year experiment (1994/95). The aim was to create a clear "window" through which a flying insect may attempt to pass (Weissling \& Knight 1994). Pane traps surfaces were compared to determine which emulsion was the most efficient at catching flying insects, and during method development only E. crataegi and S. albisignata were counted. STP is a thick, almost clear liquid, while the grease discoloured the perspex to a yellowy-brown colour. STP is able to withstand the fluctuations in temperature that occur in an orchard environment and while it became opaque with rain, it cleared after drying out. Both surfaces were lightly tacky. The traps (nine of each per block) were suspended approximately $2 \mathrm{~m}$ above the ground, inside selected apple trees within the blocks for one week, from 1 February 1995. One week later the numbers of E. crataegi and the predatory mirid Sejanus albisignata were recorded.

Subsampling

A subsampling system was tested in an attempt to increase the efficiency of pane trapping, by reducing the time involved in counting E. crataegi. The test compared a 
$10 \mathrm{~cm} \times 10 \mathrm{~cm}$ area in the centre of each of four panes ( 0.11 of the total area) with the total catch per pane in the BFP block weekly from 14 September 1995 - 11 April 1996. Correlation analysis was used to compare estimates of relative abundance of E. crataegi between sampling areas. Sampling of the full pane area was maintained for the less abundant predatory insects.

Seasonal phenology

The seasonal flight patterns of adult E. crataegi, S. albisignata and Micromus tasmaniae were monitored in each of the IFP, BFP and CFP blocks over three seasons, from 1995 to 1998. Two STP-coated sticky pane traps were placed near the centre of the BFP block and checked weekly from November to April each year. In the IFP and CFP blocks, two pane traps were monitored weekly from the beginning of December to April or May, after the start of adult E. crataegi activity in the BFP block. Both sides of the sticky panes were checked and the numbers of each insect species caught per side were recorded separately (making four trap samples per week in each block). Traps were recoated weekly.

\section{Sticky pane traps}

\section{RESULTS AND DISCUSSION}

Passive trapping of E. crataegi and S. albisignata was most successful using the trap coating of STP (Table 1), which was generally clearer. Few E. crataegi were caught by pane traps covered with a thin film of grease. Interestingly, the differences in catch between the two trapping surfaces were less for S. albisignata. This suggests that flight manoeuvrability may be greater, or that the visual component of flight is more important, for E. crataegi than S. albisignata. Other insects, such as tortricid pests, were caught in low numbers, by the pane traps but the method was not considered satisfactory for these species. Tortricid moths were difficult to identify after being immersed in the STP layer.

TABLE 1: Mean (SEM) catch per trap of E. crataegi and S. albisignata on clear sticky panes coated with STP or grease in a Canterbury apple orchard managed under biological fruit production. Traps were left out for one week.

\begin{tabular}{lcccc}
\hline Trap surface & \multicolumn{2}{c}{ E. crataegi } & \multicolumn{2}{c}{ S. albisignata } \\
\hline STP & 48.9 & $(8.5)$ & 11.0 & $(1.5)$ \\
Grease & 0.2 & $(2.0)$ & 5.6 & $(2.8)$
\end{tabular}

\section{Subsampling}

Analysis of trapping data from the BFP block indicated that counting the much smaller number of $E$. crataegi adhering to the central portion of the sticky pane trap compared with the full trap surface was equally effective for monitoring the seasonal phenology of this insect $\left(\mathrm{r}^{2}=1.0, \mathrm{df}=48\right)$. The proportion of E. crataegi trapped in the centre $(0.11$ of the area) was ca 0.13 fold of the total trapped on the whole pane, indicating that the distribution on the trap was relatively uniform. The time saving in sampling the smaller area was dependent on catch, but was significant when catches were large. For S. albisignata and $M$. tasmaniae, the entire trapping surface continued to be sampled, in order to maximise the numbers trapped.

\section{Seasonal phenology}

The comparative seasonal abundance of adult E. crataegi trapped over three seasons is shown in Fig. 1 for each orchard management system. Numbers were low in all three blocks the first season of the trial, prior to which all blocks had been sprayed with organophosphate insecticides (i.e. CFP system). Sticky pane trap monitoring 
confirmed the presence of two adult generations of E. crataegi in Canterbury, as previously reported by Teulon \& Penman (1986a). The first generation peaked midDecember, and the second during early March. Although no action threshold has been set for this insect, levels were below what could be considered serious pest status during the three years.
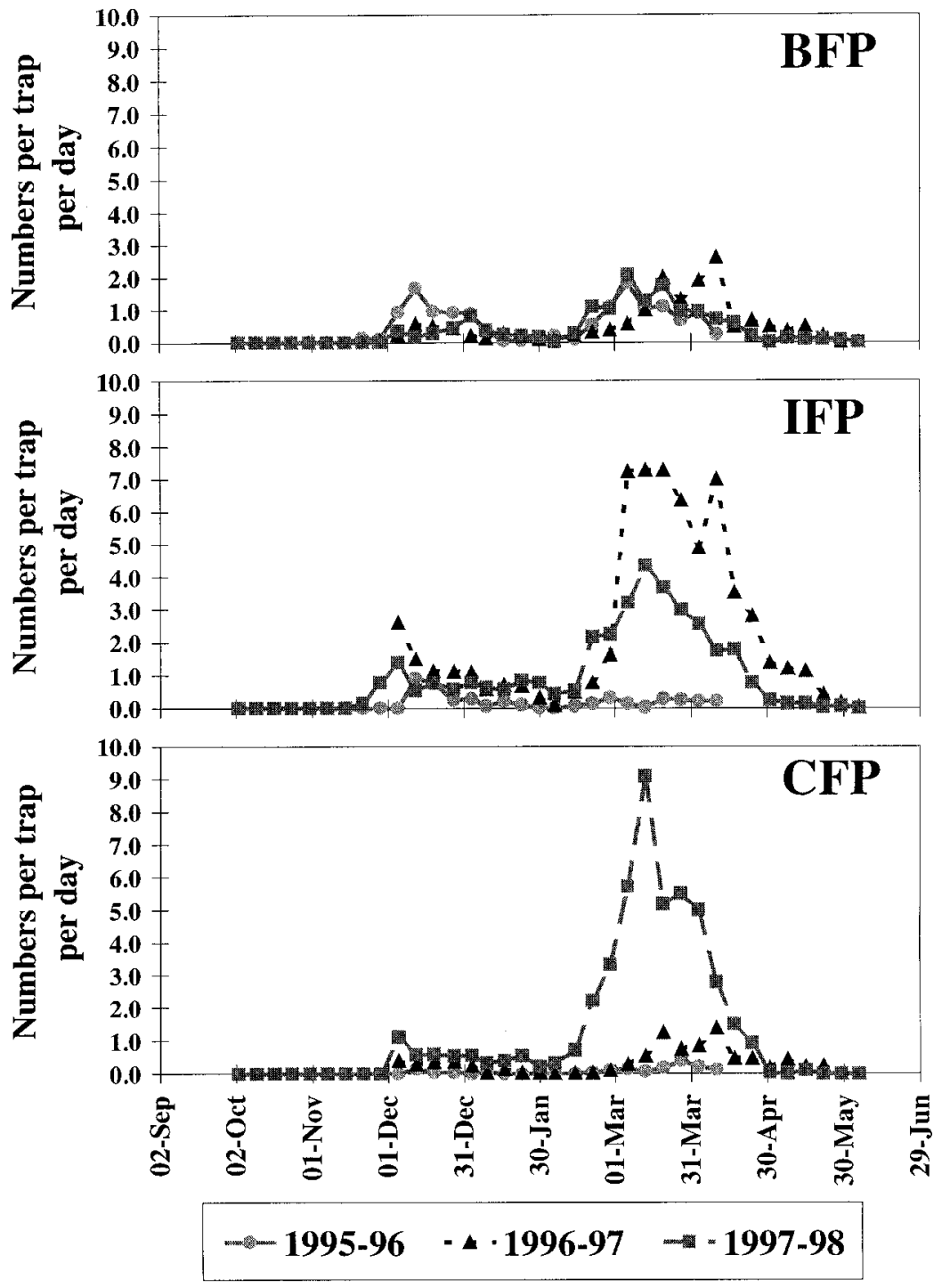

FIGURE 1: Mean catch of Froggatt's apple leafhopper on pane traps in Canterbury apple blocks managed under Biological (BFP), Integrated (IFP) or Conventional (CFP) fruit production systems over three seasons. 
There was no significant difference in the total seasonal catch of leafhoppers on each trap in the BFP block, using both sides of each of the two boards as replicates in a two way ANOVA of trap and trap side, using the three years as replicates (log-transformed). This indicates that the four trapping surfaces could be considered to be independent.

In the CFP block, numbers of adult $E$. crataegi increased substantially despite the application of organophosphate insecticides. However, the greatest numbers of E. crataegi were found within the IFP block during 1996-97 (Table 2), where numbers increased ca 8-fold from the 1995-96 season, but reduced somewhat in the third season. The lack of field control under an organophosphate (CFP) programme in the third year could suggest the possibility of insecticide resistance, as was demonstrated for Hawke's Bay (Charles et al. 1994) and Nelson (Charles 1996), but there is no direct evidence for resistance in Canterbury.

The single year with high populations under the BFP system suggests a greater role for biological control agents in this system, as well as their rapid colonisation of the block. This is despite the potentially disruptive influence of sulphur, copper and hydratedlime applied as fungicides. Alternatively this spray program may have been disruptive to E. crataegi. The use of pre-bloom oils on all three blocks prevents this from being a factor in any differences observed between management systems.

In all blocks, numbers of leafhopper adults were higher in the second generation. It is possible that the parasitoid, Anagrus sp., aided this reduction in first generation E. crataegi, but had less impact in the second generation in the CFP and IFP treatments. Teulon \& Penman (1986a) reported very high levels of parasitism (up to 100\%) of summer eggs, in his studies at a nearby location under a treatment most similar to the BFP system. There is also parasitism of over-wintering eggs (Dumbleton 1934).

TABLE 2: Mean seasonal catch of the three species on sticky traps in apple orchards under three different management systems over three seasons.

\begin{tabular}{lcccccc}
\hline \multirow{2}{*}{$\begin{array}{l}\text { Sanagement } \\
\text { System }\end{array}$} & \multicolumn{2}{c}{$1995-96$} & \multicolumn{2}{c}{$1996-97$} & \multicolumn{2}{c}{$1997-98$} \\
\cline { 2 - 7 } & Mean & SEM & Mean & SEM & Mean & SEM \\
\hline E. crataegi & & & & & & \\
BFP & 756.5 & 69.2 & 112.0 & 18.6 & 102.0 & 12.1 \\
IFP & 30.0 & 4.8 & 446.0 & 40.3 & 245.3 & 16.9 \\
CFP & 10.5 & 1.6 & 64.5 & 14.2 & 330.5 & 18.3 \\
S. albisignata & & & & & & \\
BFP & 41.8 & 8.4 & 25.5 & 6.7 & 51.0 & 4.4 \\
IFP & 23.3 & 9.4 & 71.0 & 10.9 & 45.3 & 6.1 \\
CFP & 8.0 & 0.7 & 10.3 & 1.3 & 4.3 & 1.5 \\
M. tasmaniae & & & & & & \\
BFP & 12.3 & 2.81 & 43.0 & 5.4 & 22.0 & 8.2 \\
IFP & 25.8 & 2.66 & 28.0 & 2.5 & 15.5 & 2.9 \\
CFP & 38.5 & 6.74 & 24.3 & 7.8 & 17.5 & 3.7 \\
\hline
\end{tabular}

The sticky pane trapping system was effective at detecting the flight patterns of S. albisignata adults in Canterbury (Fig. 2). In Canterbury and Central Otago, the insect has two generations per year with an occasional partial third generation in warm years (Suckling et al. 1999; Wearing \& Attfield 2001). The CFP block had fewer bugs caught on pane traps in each of the three years, compared to the IFP and BFP blocks, almost certainly due to the organophosphates used. The number of S. albisignata did not fluctuate much between years within each treatment (Table 2).

The lacewing, Micromus tasmaniae, was trapped in all blocks in similar numbers, although in 1995/96, numbers were greatest in the CFP block (Fig. 3). Peak numbers of M. tasmaniae occurred at the beginning of January, but adults were consistently found 

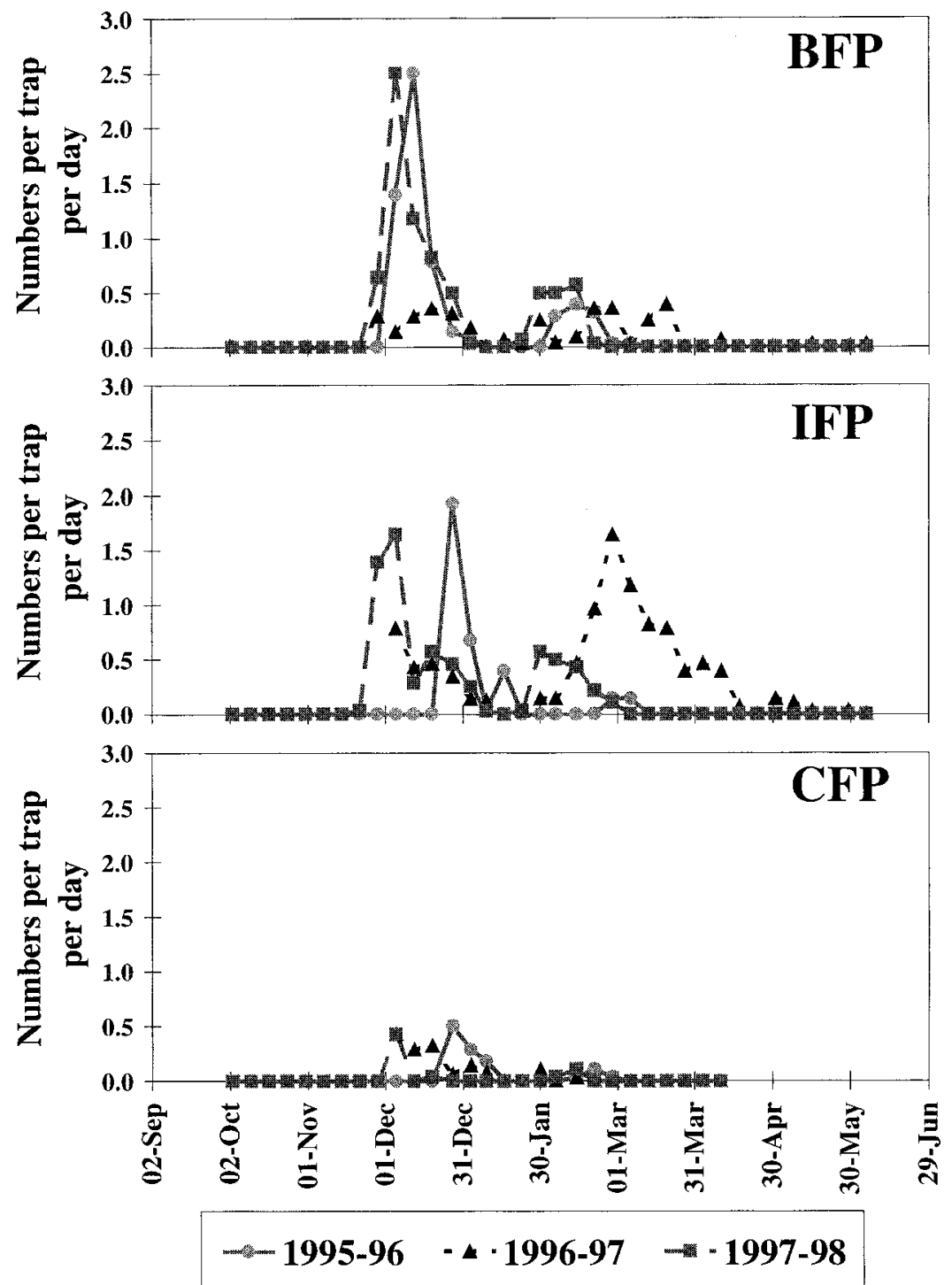

FIGURE 2: Mean catch of Sejanus albisignata on pane traps in Canterbury apple blocks managed under Biological (BFP), Integrated (IFP) or Conventional (CFP) fruit production systems over three seasons.

until the end of March, and a single generation was apparent. The role of lacewings in reducing woolly apple aphid (Eriosoma lanigerum (Hausmann)) colonies has not been quantified. While lacewings are occasionally observed feeding on woolly apple aphid colonies, their role is not thought likely to be as important as Aphelinus mali (Haldeman) 

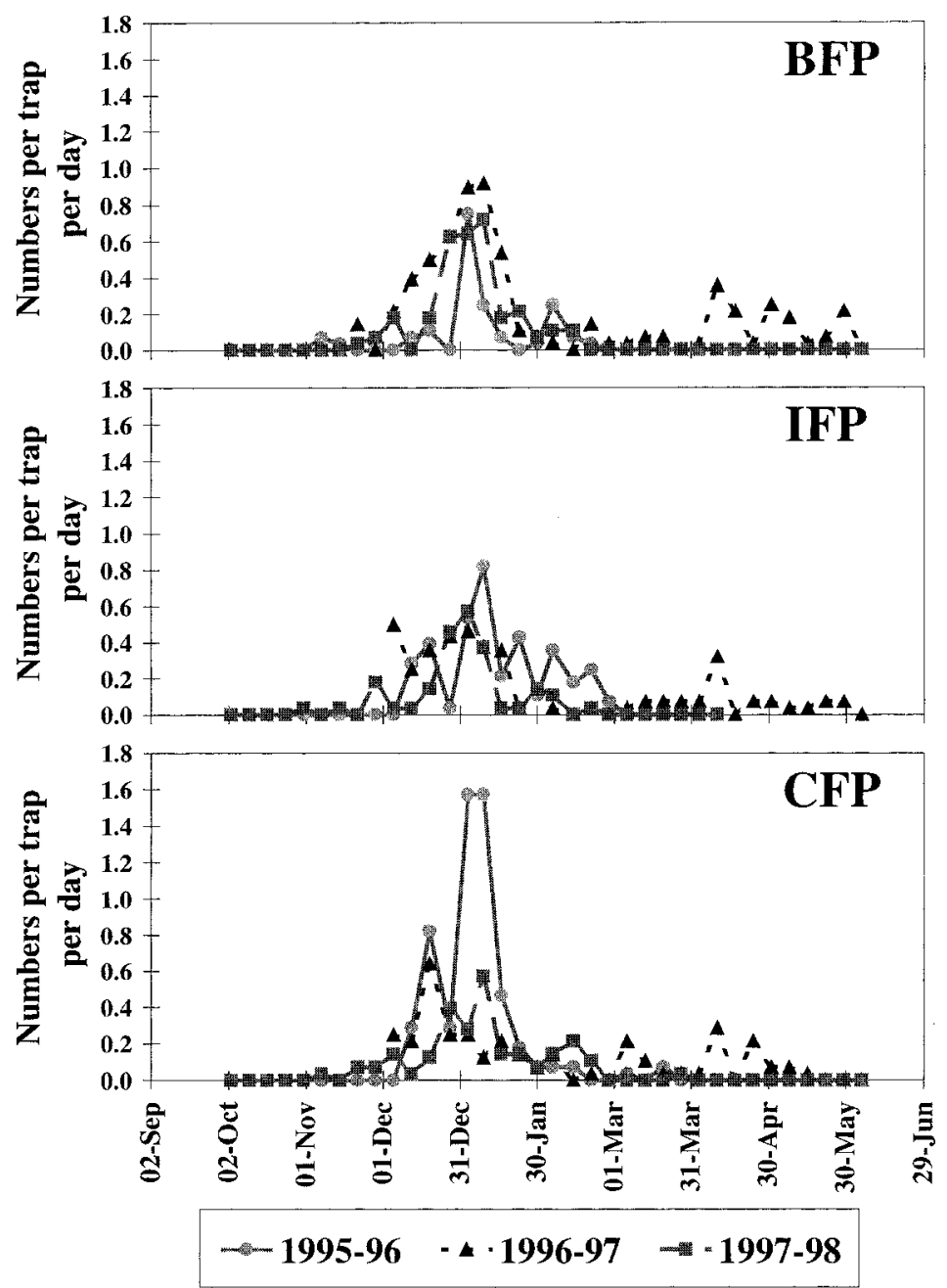

FIGURE 3: Mean catch of Micromus tasmaniae on pane traps in Canterbury apple blocks managed under Biological (BFP), Integrated (IFP) or Conventional (CFP) fruit production system over three seasons.

(Walker 1989). Micromus tasmaniae are potential predators of aphids on understory plants, species that are seldom problems on apple trees, and in this context makes their seasonal abundance in apple tree foliage more difficult to interpret. The seasonal variation in numbers of this species could be related to populations of other aphid species in land under cropping systems, although the variation detected here was not great.

Teulon \& Penman (1986b) showed that the predominant (>99.9\%) leafhopper found in one abandoned Canterbury apple orchard was E. crataegi. However, at two other orchards, additional leafhopper species were found (Teulon \& Penman 1986a). These 
were associated with either the presence of blackberry inside or outside the orchards, or an unmanaged understorey of diverse weed species. Removal of the blackberry from the orchard coincided with a decline in other leafhopper species. Furthermore, Teulon \& Penman (1987) showed that the abundance of other leafhopper species declined rapidly with sampling height. At the same height as used here, these species formed ca $0.5 \%$ of total leafhoppers. The carefully managed orchard understorey present in this study, combined with sampling well within the orchards at a suitable height suggests that the potential for occasional misidentification of leafhopper species immigrant from other host plants was unlikely to be significant.

Sticky pane trapping was found to be suitable for indicating phenology and relative abundance of one pest and two beneficial species in apple orchards. The results reconfirmed the presence of two generations of Froggatt's apple leafhopper in Canterbury. The use of pane trapping has relevance as a research tool, and may offer benefits in future studies.

\section{ACKNOWLEDGEMENTS}

This work was funded by several contracts with ENZAFRUIT and the Foundation for Research, Science and Technology. We are grateful to a range of summer students for assistance with the field work.

\section{REFERENCES}

Batchelor, T.A.; Walker, J.T.S.; Manktelow, D.W.L.; Park, N.M.; Johnson, S.R. 1997: New Zeland integrated fruit production for pipfruit: Charting a new course. Proc. 50th N.Z. Plant Prot. Conf.: 14-19.

Bradley, S.J.; Walker, J.T.S.; Wearing, C.H.; Shaw, P.W.; Hodson, A.J. 1998: The use of pheromone traps for leafroller action thresholds in pipfruit. Proc. 51st N.Z. Plant Prot. Conf.: 173-178.

Charles, J.G. 1989: Edwardsiana crataegi (Douglas) (=Typhlocyba froggatti Baker), Froggatt's apple leafhopper (Homoptera: Cicadellidae). In: Cameron, P.J.; Hill, R.L.; Bain, J.; Thomas, W.P. ed. A Review of Biological Control of Insect Pests and Weeds in New Zealand 1874 to 1987. Technical Communication, CAB International Institute of Biological Control 10, CAB International, Wallingford, U.K. Pp. 183-186.

Charles, J.G.; Walker, J.T.S.; White, V. 1994: Resistance in Froggatt's apple leafhopper Edwardsiana crataegi Douglas, to azinphos-methyl. Proc. 47th N.Z. Plant Prot. Conf.: 333-336.

Charles, J.G. 1996. Can buprofezin control Froggatt's apple leafhopper, Edwardsiana crataegi? Proc. 49th N.Z. Plant Prot. Conf.: 81-84.

Collyer, E.; van Geldermalsen, M. 1975: Integrated control of apple pests in New Zealand 1. Outline of experiment and general results. N.Z. J. Zool. 2: 101-134.

Dumbleton, J.L. 1934:. The apple leafhopper (Typhlocyba australis Frogg.). N.Z. J. Sci. Tech. 16: 30-38.

Suckling, D.M.; Gibb, A.R.; Burnip, G.M.; Stavely, F.I.J.; Wratten, S.D. 1996: Comparison of suction and beating tray sampling for apple pests and their natural enemies. Proc. 49th N.Z. Plant Prot. Conf.: 41-47.

Suckling, D.M.; Walker, J.T.S.; Wearing, C.H. 1999: Ecological impact of three pest management systems in New Zealand apple orchards. Agric. Ecosystems Environ. 73: $129-140$.

Teulon, D.A.J.; Penman, D.R. 1984: Spray timing for control of Froggatt's apple leafhopper in Canterbury. Proc. 37th N.Z. Weed and Pest Control Conf.: 245-247.

Teulon, D.A.J.; Penman, D.R. 1986a: Sticky board sampling of leafhoppers in three apple orchards under different management regimes. N.Z. J. Agric. Res. 29: 289298. 
Teulon, D.A.J.; Penman, D.R. 1986b: Temporal distribution of Froggatt's apple leafhopper (Typhlocyba froggatti Baker) and the parasite Anagrus armatus (Ashmead) in an abandoned orchard. N.Z. J. Zool. 13: 93-100.

Teulon, D.A.J.; Penman, D.R. 1987: Vertical stratification of sticky board catches of leafhopper adults (Hemiptera: Cicadellidae) within apple orchards. N.Z Entomol. 9: 100-103.

Thomas, W.P; Walker, J.T.S. 1989: Tetranychus urticae Koch, two-spotted mite (Acari: Tetranychidae). In: Cameron, P.J.; Hill, R.L.; Bain, J.; Thomas, W.P. ed. A Review of Biological Control of Insect Pests and Weeds in New Zealand 1874 to 1987. Technical Communication, CAB International Institute of Biological Control 10, CAB International, Wallingford, U.K. Pp. 245-250.

Walker, J.T.S. 1989: Eriosoma lanigerum (Hausmann), woolly apple aphid In: Cameron, P.J.; Hill, R.L.; Bain, J.; Thomas, W.P. ed. A Review of Biological Control of Invertebrate Pests and Weeds in New Zealand 1874 to 1987. Technical communication, $\mathrm{CAB}$ International Institute of Biological Control 10, CAB International, Wallingford, UK. Pp.197-199.

Walker, J.T.S.; Wearing, C.H.; Hayes, A.J. 1989: Panonychus ulmi (Koch), European red mite (Acari: Tetranychidae). In: Cameron, P.J.; Hill, R.L.; Bain, J.; Thomas, W.P. ed. A Review of Biological Control of Invertebrate Pests and Weeds in New Zealand 1874 to 1987. Technical communication, CAB International Institute of Biological Control 10, CAB International, Wallingford, UK. Pp. 217-221.

Wearing, C.H.; Charles, J.G. 1989. Cydia pomonella (L.), codling moth (Lepidoptera: Tortricidae). In: Cameron, P.J.; Hill, R.L.; Bain, J.; Thomas, W.P. ed. A Review of Biological Control of Insect Pests and Weeds in New Zealand 1874 to 1987. Technical Communication, CAB International Institute of Biological Control 10, CAB International, Wallingford, U.K. Pp. 161-169.

Wearing, C.H.; Attfield, B. 2001: Phenology of the predatory bugs Orius vicinus (Heteroptera: Anthocoridae) and Sejanus albisignata (Heteroptera: Miridae) in Otago, New Zealand, apple orchards. Biocontrol, Sci. Technol. Submitted.

Weissling, T.J.; Knight, A.L. 1994: Passive trap for monitoring codling moth (Lepidoptera: Tortricidae) flight activity. J. Econ. Entomol. 87: 103-107. 